\title{
Analysis of Regional Differences of Chinese Star Hotels Based on GIS
}

\author{
Chen Hui', Zhu Shuguang ${ }^{1}$, He Kuan ${ }^{1}$, ZHOU Zhimin ${ }^{2, *}$ \\ (1.Surveying and Mapping Engineering, Yellow River Conservancy Technical Institute, \\ Kaifeng ,475004,China; \\ 2. College of Environment and Placnning, Henan University, Kaifeng, 475004, China)
}

Key Word: GIS; star-hotel; time and spatial layout; dynamic factor model

Abstract: This paper combines the attribute data and spatial distribution data of star hotels in different provinces and cities in China, and uses the methods of correlation analysis and location entropy to quantitatively analyze the spatial and temporal distribution of star hotels in China, and explore the dynamic factors that influence the distribution pattern, and construct the dynamic model which affects its distribution pattern. The results showed that: China star hotel development level from east to west in the ladder-like distribution, regional gap is larger, the highest level of development area of Beijing and the eastern coastal area, central form obviously less developed area, low level of star hotel development area is located in the west, and the northeast, southwest provinces needs further development; Star hotels in the central and western regions grew faster than the eastern region, but due to the low starting point, the total amount is small, its absolute difference with the eastern region has been expanding; The spatial and temporal distribution pattern of star hotels is a reflection of the unbalanced development of regional economy and tourism.

\section{Introduction}

The city hotel industry is one of the important departments in the tertiary industry. The development of China's hotel industry began in the early 80 s. In recent years, with the development of social economy and tourism, the city hotel industry has been developing rapidly. On the city hotel industry research is also increasing, $\mathrm{Ji}$ Wen from the perspective of management, quantitative analysis of the spatial distribution of China's hotel industry ${ }^{[1]}$. Ruilin Yu and Hong Zhang discussed the characteristics and rules of the spatial distribution of star hotels in Wuhan city ${ }^{[2]}$, Haining Jiang et al analyzed the distribution characteristics of Nanjing city hotel, and sums up the factors affecting the distribution of ${ }^{[3]}$, Wei Tao et al with hotel as a case study of Guangzhou city space layout and commercial layout relationship ${ }^{[4]}$. Although the above studies involve a lot of star hotel space layout of the article, but the research method is mainly based on qualitative analysis, and research content is mainly based on the description of spatial distribution characteristics, not related to time, scope is also limited to some specific cities. Therefore, this article from the star hotel of the country's macro perspective, using GIS tools, use of combination of qualitative and quantitative analysis method, to explore the time and space distribution characteristics of hotel industry of China, to study the spatial structure adjustment and optimization rule.

\section{Data Sources and Research Methods}

\section{Data Sources}

This article star hotel definition uses since May 1, 1998 to start with "the tourism foreign hotel 
stars classification and the appraisal" (GB / T14308-93) standard. In addition, the star hotels in this study, including all one to five-star hotel, and to the China Tourism Bureau statistics data shall prevail.

Preparation of the National Tourism Administration "Chinese Tourism Statistical Yearbook" recorded in the calendar year of the star hotel, the provinces (autonomous regions) the basic situation and the important tourist city hotel, including star hotel, hotel type, scale, star hotel number, room number, room occupancy rate, the number of beds, business income. The data required in this paper is mainly obtained from the China Statistical Yearbook of tourism in 2000-2014.

China's Hong Kong special administrative region, Taiwan region, the Macao special administrative region shall be respectively have their own independent star hotel statistics system, in order to reduce the interference and the difficulty of data collection, this paper eliminated the Hong Kong special administrative region and Taiwan region, the Macao special administrative region, therefore, the three regions as the research scope.

\section{Research Methods}

In regional economics, geography and other related theory as the instruction, with the aid of GIS technology, with the support of Mapinfo software, to achieve the star class hotel industry analysis of large amounts of data processing in our country, according to the characteristics of the software and the research needs, will receive the graphics data stored in a graphics file, the relevant attribute data stored in relational database, graphic data and attribute data through a unique identification code connection. Graphic data according to research needs are divided into four thematic layers, respectively, the basic administrative divisions of China's provinces and municipalities, China's GDP distribution map, provinces and cities in China and the distribution map of China's provinces and cities star hotel distribution map.

Based on the above thematic layers and data, through the establishment of attribute database, thematic mapping, query analysis, such as overlay analysis, buffer analysis and a series of operations, get the star hotel in various provinces and cities of the spatial density distribution, through further analysis and processing, Derived Chinese star hotel space-time distribution characteristics.

\section{Analysis of the Spatial and Temporal Distribution Characteristics of Chinese Star Hotels}

\section{Time Distribution Characteristics of China's Star Hotel}

Since 2001 to 2013, the characteristics of the time distribution of the data more obvious, coupled with data collection restrictions, so this paper selected from 2001 to 2013 data to analyze the time distribution of Chinese star hotel characteristics. By 2001 to 2013 of China's star hotel data is analyzed, the results are shown in table 1.

Table 1 Star Hotel Number and Turnover of Provinces and Cities, the Growth Rate of Comparison table

\begin{tabular}{|c|c|c|c|c|c|c|}
\hline & \multicolumn{3}{|c|}{ Number of Hotels（A，\%) } & \multicolumn{3}{|c|}{ Turnover (Billion, \%) } \\
\hline & In 2001 & In 2013 & Growth rate & In 2001 & In 2013 & Growth rate \\
\hline Beijing & 508 & 577 & 0.136 & 121.2 & 276.6 & 1.282 \\
\hline Tianjin & 80 & 93 & 0.163 & 10.7 & 26.6 & 1.483 \\
\hline Hebei & 226 & 409 & 0.810 & 19.3 & 67.5 & 2.500 \\
\hline Shanxi & 189 & 272 & 0.439 & 9.8 & 44.5 & 3.545 \\
\hline Inner Mongolia & 111 & 268 & 1.414 & 5.9 & 29.6 & 4.009 \\
\hline
\end{tabular}




\begin{tabular}{|c|c|c|c|c|c|c|}
\hline Liaoning & 285 & 421 & 0.477 & 28.8 & 76.5 & 1.655 \\
\hline Jilin & 137 & 189 & 0.380 & 7.6 & 24.7 & 2.244 \\
\hline Heilongjiang & 221 & 223 & 0.009 & 10.5 & 21.9 & 1.090 \\
\hline Shanghai & 300 & 256 & -0.147 & 86.8 & 166.9 & 0.923 \\
\hline Jiangsu & 565 & 735 & 0.301 & 60.5 & 175.3 & 1.897 \\
\hline Zhejiang & 610 & 828 & 0.357 & 81.4 & 207.6 & 1.551 \\
\hline Anhui & 215 & 377 & 0.753 & 10.9 & 53.6 & 3.915 \\
\hline Fujian & 230 & 401 & 0.743 & 17.2 & 97.3 & 4.657 \\
\hline Jiangxi & 185 & 341 & 0.843 & 6.6 & 34.3 & 4.194 \\
\hline Shandong & 342 & 792 & 1.316 & 35.4 & 135.9 & 2.839 \\
\hline Henan & 242 & 362 & 0.496 & 8.6 & 43.4 & 4.051 \\
\hline Hubei & 460 & 378 & -0.178 & 16.9 & 48.5 & 1.872 \\
\hline Hunan & 166 & 414 & 1.494 & 10.4 & 69.3 & 5.666 \\
\hline Guangdong & 640 & 917 & 0.433 & 117.3 & 244.1 & 1.081 \\
\hline Guangxi & 246 & 381 & 0.549 & 17.1 & 42.1 & 1.461 \\
\hline Hainan & 157 & 150 & -0.045 & 10.1 & 46.1 & 3.568 \\
\hline Chongqing & 69 & 234 & 2.391 & 9 & 42.1 & 3.678 \\
\hline Sichuan & 204 & 461 & 1.260 & 14.6 & 84.5 & 4.787 \\
\hline Guizhou & 58 & 305 & 4.259 & 3.5 & 24.7 & 6.057 \\
\hline Yunnan & 431 & 563 & 0.306 & 10.9 & 65.2 & 4.986 \\
\hline Tibet & 12 & 109 & 8.083 & 0.8 & 6.1 & 6.578 \\
\hline Shanxi & 141 & 333 & 1.362 & 11.6 & 48.8 & 3.209 \\
\hline Gansu & 97 & 304 & 2.134 & 5.9 & 24.9 & 3.228 \\
\hline Qianghai & 29 & 125 & 3.310 & 1.5 & 8.5 & 4.694 \\
\hline Ningxia & 29 & 84 & 1.897 & 2.2 & 10.6 & 3.832 \\
\hline Xijiang & 173 & 385 & 1.225 & 10.1 & 45.0 & 3.457 \\
\hline
\end{tabular}

(Data sources: 《China's tourism yearbook》2001, 2013)

This 13 years, the number of stars from the hotel to see the change, the fastest growing is Tibet, followed by Guizhou, Qinghai, Chongqing. From the star hotel business income changes in Tibet, Guizhou, Hunan and Yunnan are the fastest, followed by the rest of the steady development of the rest of the region. Midwest star-rated hotel industry to rise rapidly in the eastern region, from the data, you can see that this is mainly due to the Midwest star-rated hotel low level, small volume, Such as the number of star hotels in Tibet is 12 in 2001, in 2013 increased to 109, although the speed is quite fast, but the star hotel space distribution density was 0.1 and 0.85 in 2001 and 2013, is The country's least. Therefore, the star hotels in the central and western regions grow faster, the relative differences in regional hotel industry development will continue to shrink, but the absolute difference with the eastern region has been expanding.

\section{The Spatial Distribution Characteristics of Chinese Star Hotels}

From 2000 to 2013 of China's star hotel space distribution pattern is similar, is now in the distribution of 2012 as an example, the spatial distribution pattern of roughly as follows.

Provincial Difference Is Big, Concentration Degree Is High

Basic distribution of star hotels in China in 2012 as shown in figure 1, in general, no matter in star hotel development initial period or in the near future, China's star hotel number, density, specific gravity of the provinces (municipalities directly under the central government, autonomous 
regions) difference is very big. As can be seen from Table 2, the star hotels the most intensive places in the top three followed by Shanghai, Beijing, Tianjin. But the density of Shanghai is 1.31 times that of Beijing and 4.85 times of that of Tianjin. We can see that the distribution of China's star hotel makes the star hotel is very concentrated. From the graph can be drawn: Chinese star hotel formed the north, South and Middle, the three large distribution of high density areas, a north of Beijing City, Tianjin City, a south of Guangdong Province, refers to the Jiangsu、Zhejiang and Shanghai area.

Table 2 China's star hotel hotel number and density of comparison of provinces and cities

\begin{tabular}{|c|c|c|c|c|c|c|}
\hline & \multicolumn{3}{|c|}{ Number of hotels (A) } & \multicolumn{3}{|c|}{$\begin{array}{c}\text { The density of the hotel } \\
\text { (A/ million square kilometers) }\end{array}$} \\
\hline & In 2001 & In 2006 & In 2012 & In 2001 & In 2006 & In 2012 \\
\hline Beijing & 508 & 700 & 584 & 302.38 & 416.67 & 347.62 \\
\hline Tianjin & 80 & 112 & 103 & 72.73 & 101.82 & 93.64 \\
\hline Hebei & 226 & 382 & 404 & 12.04 & 20.35 & 21.52 \\
\hline Shanxi & 189 & 305 & 280 & 12.09 & 19.51 & 17.91 \\
\hline Inner Mongolia & 111 & 224 & 245 & 0.94 & 1.90 & 2.07 \\
\hline Liaoning & 285 & 497 & 399 & 19.53 & 34.06 & 27.34 \\
\hline Jilin & 137 & 210 & 192 & 7.31 & 11.21 & 10.24 \\
\hline Heilongjiang & 221 & 265 & 236 & 4.71 & 5.65 & 5.03 \\
\hline Shanghai & 300 & 317 & 281 & 484.97 & 512.45 & 454.26 \\
\hline Jiangsu & 565 & 799 & 732 & 55.07 & 77.88 & 71.35 \\
\hline Zhejiang & 610 & 1023 & 783 & 59.92 & 100.49 & 76.91 \\
\hline Anhui & 215 & 345 & 383 & 16.54 & 26.54 & 29.46 \\
\hline Fujian & 230 & 437 & 390 & 18.98 & 36.06 & 32.18 \\
\hline Jiangxi & 185 & 301 & 303 & 11.56 & 18.81 & 18.93 \\
\hline Shandong & 342 & 645 & 796 & 22.35 & 42.15 & 52.02 \\
\hline Henan & 242 & 468 & 339 & 14.49 & 28.02 & 20.30 \\
\hline Hubei & 460 & 578 & 367 & 24.73 & 31.07 & 19.73 \\
\hline Hunan & 166 & 501 & 449 & 7.90 & 23.84 & 21.37 \\
\hline Guangdong & 640 & 1146 & 927 & 35.56 & 63.67 & 51.51 \\
\hline Guangxi & 246 & 374 & 339 & 10.42 & 15.84 & 14.36 \\
\hline Hainan & 157 & 261 & 155 & 46.18 & 76.77 & 45.59 \\
\hline Chongqing & 69 & 211 & 240 & 8.41 & 25.72 & 29.25 \\
\hline Sichuan & 204 & 485 & 396 & 3.60 & 8.56 & 6.99 \\
\hline Guizhou & 58 & 219 & 290 & 3.41 & 12.88 & 17.05 \\
\hline Yunnan & 431 & 867 & 480 & 10.94 & 22.01 & 12.18 \\
\hline Tibet & 12 & 62 & 102 & 0.10 & 0.52 & 0.85 \\
\hline Shanxi & 141 & 280 & 283 & 6.86 & 13.62 & 13.77 \\
\hline Gansu & 97 & 232 & 287 & 2.13 & 5.09 & 6.30 \\
\hline Qianghai & 29 & 97 & 84 & 0.40 & 1.34 & 1.16 \\
\hline Ningxia & 29 & 48 & 77 & 4.37 & 7.23 & 11.60 \\
\hline Xijiang & 173 & 360 & 441 & 1.04 & 2.16 & 2.65 \\
\hline
\end{tabular}

(Data sources: 《China's tourism yearbook》2001,2006,2012。) 


\section{a. From East to West, the Development Level of Star Hotels in China Successively Decreased}

From Figure 1 can be clearly seen from east to west from black to gray to greyish white, brightness increased gradually, Chinese star hotel density from the high level of 454.26 and gradually decreased to a low level of 0.85 : from east to west down the trend is very clear.

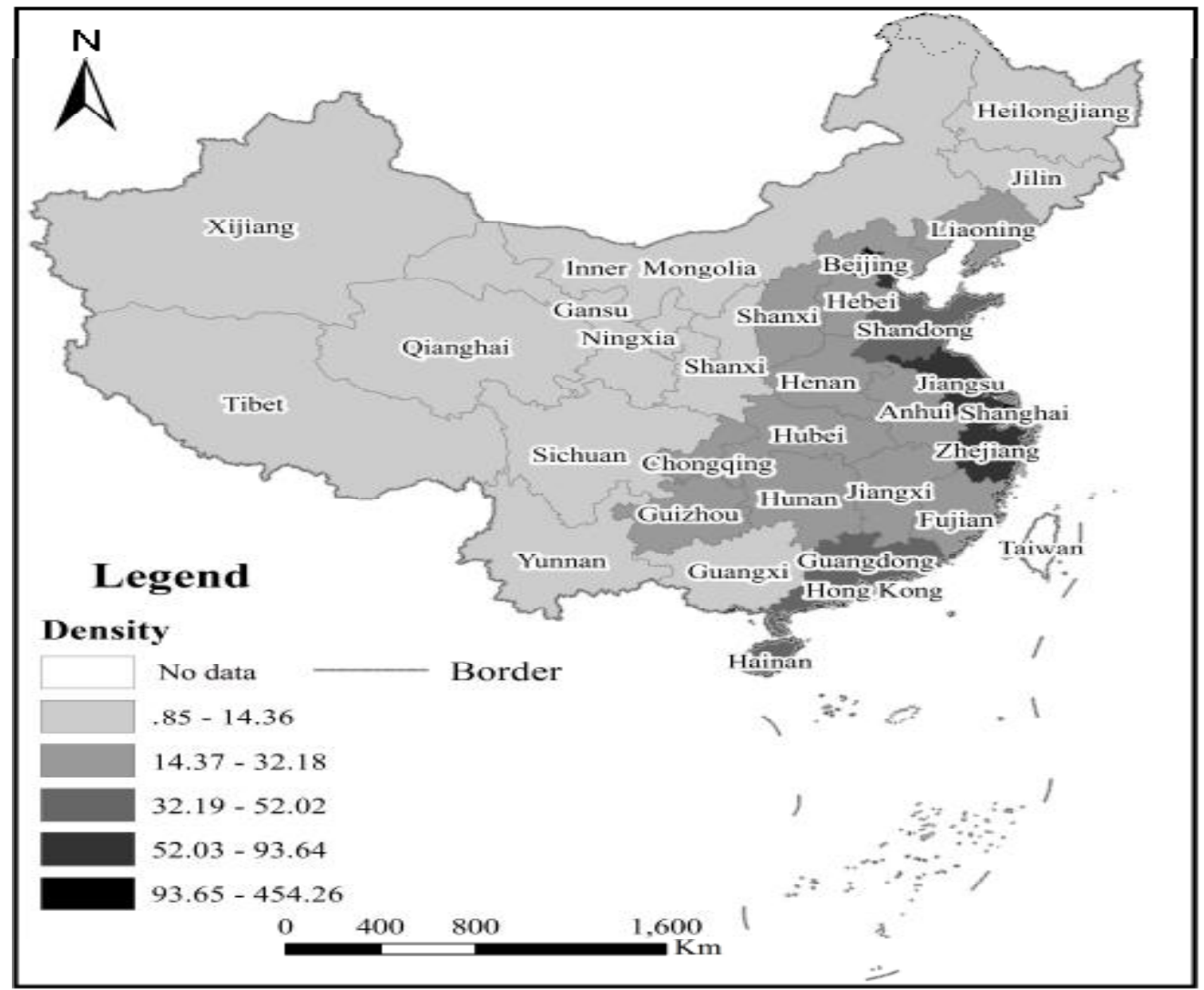

Fig 1 The density distribution of Chinese star hotels in 2012

Level of China's star hotel development areas of high and low level of China's star hotel development area density basically unchanged, but the density difference between area, such as at the highest level of Shanghai and Beijing area, has accounted for $7.61 \%$ of the total number of star hotel; At the lowest level is Qinghai and Tibet, the number of star hotels accounted for only $1.63 \%$ of the total, high-end is 4.65 times than low-end. At the same time, the high level area (black area) is the 88.72 times of the density of the star hotels in the low level area (gray white area). These extreme data increases the overall discrete degree ${ }^{[7]}$; In the practical sense, eastern and western region is characterized by large difference of the Chinese star hotel.

\section{b. The Highest Level of Development for the Region of Beijing and the Eastern Coastal Areas}

At the same time, we can see that China's high-star hotel development areas are concentrated in the capital Beijing and the eastern coastal areas, including Guangdong Province, Shanghai city, Jiangsu Province, Zhejiang Province, Shandong Province and Fujian Province. The number of these regions accounted for $23 \%$ of the country, but the total number of star hotels accounted for $38.76 \%$ of the country; it is seen that the development of star hotels in these areas is much higher than the national average.

\section{c. The Middle Area of the Formation of a Very Oobvious Sub-Developed Areas}

Liaoning Province, Hebei Province, Tianjin City, Henan Province, Hubei Province, Hunan Province and Sichuan Province are connected to each other to form an obvious central 
sub-developed area. The number of their regions accounted for $23 \%$ of the country, the total star hotels accounted for $21.62 \%$ of the country.

\section{d. Low Level of Development in the Western Region, While the Northeast and Southwest Provinces to Be Developed}

Low development level of China's star hotels are mostly concentrated in the western region, including 10 regions (except Sichuan province), the number of regions accounted for $32.3 \%$ of the country, but only $23.12 \%$ of the total number of star hotels. However, different areas have their own characteristics: (1) The development of star hotels in the three northeastern provinces is relatively low. Except Liaoning Province, Heilongjiang Province and Jilin Province are lower than the national average level, but Jilin Province has developed rapidly. (2) in addition to sichuan province, southwest of star hotel development is generally lag behind; (3) the northwest region including the star hotel of the least developed in qinghai province and the Tibet autonomous region, is the development level of the lowest; Qinghai province star hotel number only 84 of them; From the national perspective, Jiangxi Province, Guangxi autonomous region and Guizhou province development level in neighboring regions. The number of neighboring regions of star hotels in Guizhou province are more than 300, such as Yunnan province in 480, the Guangxi autonomous region has 339, Hubei has 367, Hunan has 449, but only 290 in Guizhou province.

China Star Hotel Is a Ribbon Distribution

After a period of time, the development of China star hotels has formed a pattern of spatial distribution. From 2012 China's regional distribution of star hotels location entropy ${ }^{[6]}$ (Use Q to indicate) (Figure 3, Table 3), you can simply divide China into four categories: The first kind of region location entropy $\mathrm{Q}>10$, including Shanghai and Beijing, their location entropy are respectively 54.18 and 36.42, Shanghai and Beijing is the most populated areas, the national star hotel the two regions in the number of the hotel, the density is far ahead in the country; The second area $5<\mathrm{Q}<10$, such regions include Tianjin, Jiangsu, Zhejiang, Guangdong, Hainan, the five star hotel in the coastal cities are numerous, the density of the star hotel is big also, in the star hotel of a fairly large proportion of; The second category of regional entropy is $5<\mathrm{Q}<10$, such areas include Tianjin, Jiangsu, Zhejiang, Guangdong, Hainan, the five coastal cities, a large number of star hotels, star hotel density is large, Class hotel in the proportion is relatively large; Third types of regional entropy $1<\mathrm{Q}<5$, including Hebei, Shanxi, Liaoning, Jilin, Anhui, Fujian, Jiangxi, Shandong, Henan, Hubei, Hunan, Guangxi, Chongqing, Yunnan,, Shaanxi, its location entropy is in turn1.65、1.5、 $2.58 、 1.02 、 2.27 、 2.50 、 1.16 、 3.12 、 2.13 、 2.87 、 1.68 、 1.23 、 1.78 、 1.44$ and 1.10; The fourth class area of location entropy is $0<\mathrm{Q}<1$, including Inner Mongolia, Heilongjiang, Sichuan, Guizhou, Tibet, Gansu, Qinghai, Ningxia, Xinjiang.

Table 3 China's Provinces Star Hotel Location Entropy

\begin{tabular}{|c|c|c|c|c|c|}
\hline Region & Location entropy & Category & Region & Location entropy & Category \\
\hline Shanghai & 54.18 & 1 & Shanxi & 1.5 & 3 \\
\hline Beijing & 36.42 & 1 & Yunnan & 1.44 & 3 \\
\hline Tianjin & 7.84 & 2 & Guangxi & 1.23 & 3 \\
\hline Zhenjiang & 7.14 & 2 & Jiangxi & 1.16 & 3 \\
\hline Hainan & 5.8 & 2 & Shanxi & 1.1 & 3 \\
\hline Jiangsu & 5.7 & 2 & Jilin & 1.02 & 3 \\
\hline Guangdong & 5.33 & 2 & Guizhou & 0.65 & 4 \\
\hline Shandong & 3.12 & 3 & Sichuan & 0.61 & 4 \\
\hline
\end{tabular}




\begin{tabular}{cccccc}
\hline Hubei & 2.87 & 3 & Ningxia & 0.49 & 4 \\
Liaoning & 2.58 & 3 & Heilongjiang & 0.43 & 4 \\
Fuajian & 2.5 & 3 & Gansu & 0.34 & 4 \\
Anhui & 2.27 & 3 & Xinjiang & 0.14 & 4 \\
Henan & 2.13 & 3 & Inner Mongolia & 0.11 & 4 \\
Chongqing & 1.78 & 3 & Qianghai & 0.06 & 4 \\
Hunan & 1.68 & 3 & Tibet & 0.05 & 4 \\
Hebei & 1.65 & 3 & & & \\
\hline
\end{tabular}

Data sources: 《China's tourism yearbook 2012》calculated。

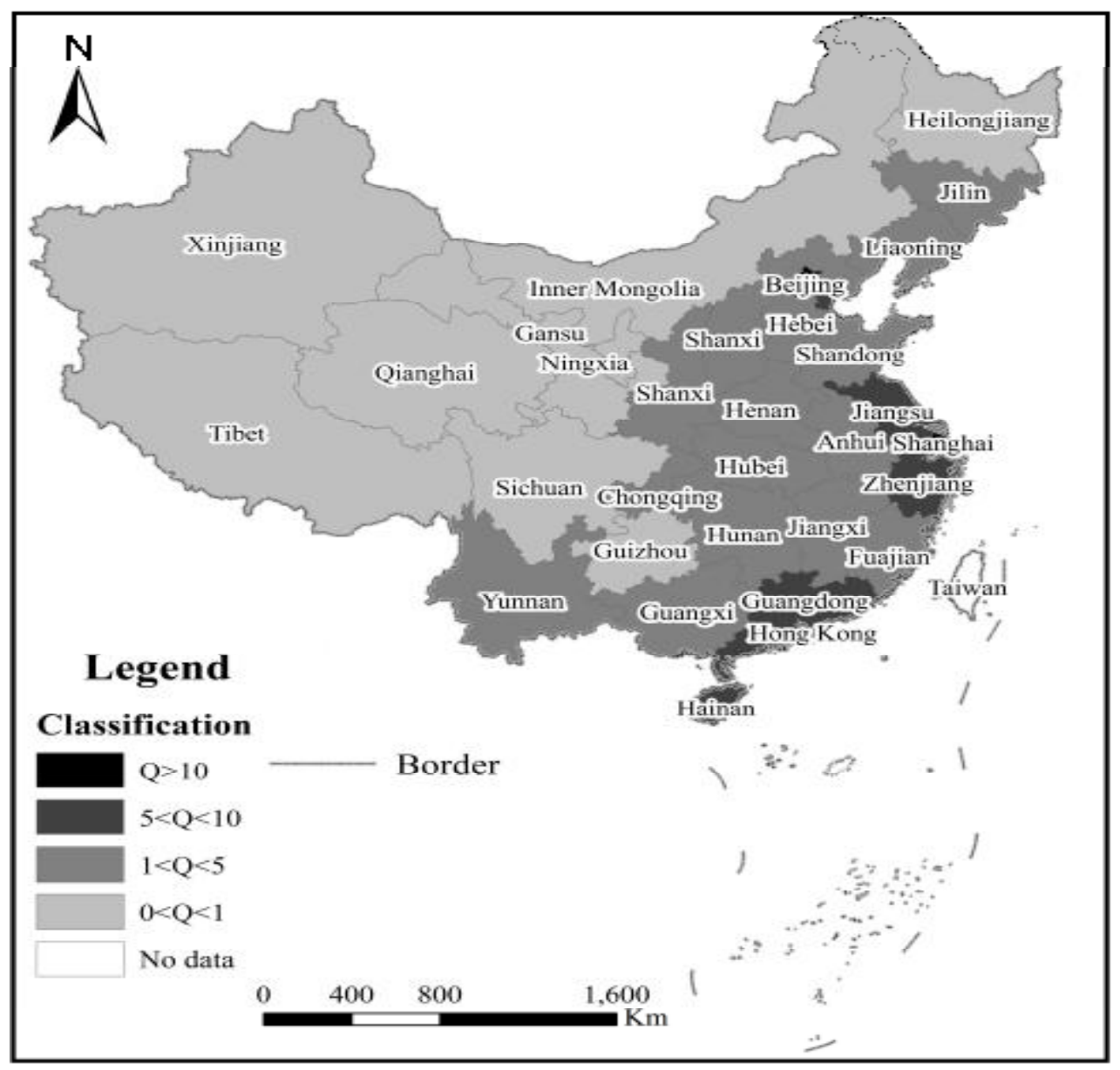

Fig2 The Location Entropy Distribution of Star Hotels in Various Provinces and Cities

\section{Dynamic Factor and Dynamic Model of the Spatial Distribution of Chinese Star Hotels}

The spatial and temporal distribution of star hotels in China is the result of many complex factors. The development characteristics of spatial distribution of star hotels China and Chinese economic area is basically the same, can also be said that the difference of regional economy is the main factor causing the regional differences in the spatial distribution of star hotels Chinese ${ }^{[7]}$. This article will influence from the Chinese star hotel space layout of the natural and social economic factors to ${ }^{[8]}$, to explore the influence the power factor of the spatial distribution of star-rated hotels in China. 


\section{To Explore the Spatial Distribution Power Factor and its Analysis}

As to the construction of the power system of tourism development, there are many domestic researches. For example, $\mathrm{Hu} \mathrm{Yu}$ et al has classified the power system of urban tourism development into four parts: the demand system, the intermediary system, the gravitation system and the support system, so as to construct the tourism dynamic system ${ }^{[9]}$; Just to protect the tourist city development as eight dynamic factors, namely the level of city development, foreign economic relations, the city culture atmosphere, tourist attractions, geographical features, infrastructure, environment quality and the service level ${ }^{[10]}$. Star hotel industry is a key part of tourism development. Therefore, this paper, based on the research results of other scholars in the development of dynamic mechanism of star hotels, selected six major dynamic factors: Consumption factors, tourism factors, business factors, investment factors, traffic factors and urban factors, and the link between the factors is shown in figure 3.

(1) Consumption factor: mainly from the consumer demand for the market stimulus mechanism to analyze the star hotel space layout. Market by the consumer, consumer demand and ability to pay to decide ${ }^{[11]}$. Therefore, this article from the urban residents income, per capita GDP, population and other indicators to measure the consumption of several star hotel and then explore the star hotel space layout is reasonable and so on.

(2) Tourism factor: the city's tourism industry has a direct pull on the consumption of the star hotel, due to the development of regional tourism, so as to promote the development of regional hotel industry, hotel space layout. This paper chooses tourism resources, the power factor number to represent the travel agency, travel basically can be summarized as a kind of tension for the important role in the hospitality industry.

(3) Business factors: the development of regional business, and promote the region's flow of people, logistics and information flow of prosperity, the hotel industry also has a stimulating effect $^{[12]}$. The hotel's proximity to the city's commercial center or the business bustle surrounding the hotel is one of the attractions of the hotel. Business developed areas, especially the city CBD generally good economic base, internal and external economic exchanges are more frequent, more conference and exhibition activities, consumer purchasing power is strong, the star hotel market demand is also great. In this paper, trade factor selection of trade, catering, wholesale and retail.

(4) Investment factors: investment in a region, especially in fixed assets investment, the economic development of the region, stimulating domestic demand and other important role, including the construction of star hotels. Therefore, the investment in fixed assets also has a positive role in promoting the space layout of star hotels ${ }^{[13]}$.

(5) Traffic factor: convenient transportation system for the regional flow of people to create the basic condition, so the traffic conditions can be used as a hotel support system in the power system. Traffic conditions are important factors affecting the location of the hotel, close to station, port and urban traffic trunk road area, because people is more, traffic is big, has the value of setting up shop. On the corner of the intersection, the traffic is very convenient, high visibility, is also a good place for setting up. Therefore, the status of traffic development is also an important factor in the layout of the star hotel space.

(6) urban factor: from the perspective of the spatial layout of the hotel, mainly concentrated in the city, especially the large and medium-sized cities. The development of urban economy and the construction of urban infrastructure reflect the attractiveness of a city to tourists, which is also an important factor in promoting the spatial distribution of hotels. 


\section{The Construction of a Dynamic Model and Analysis}

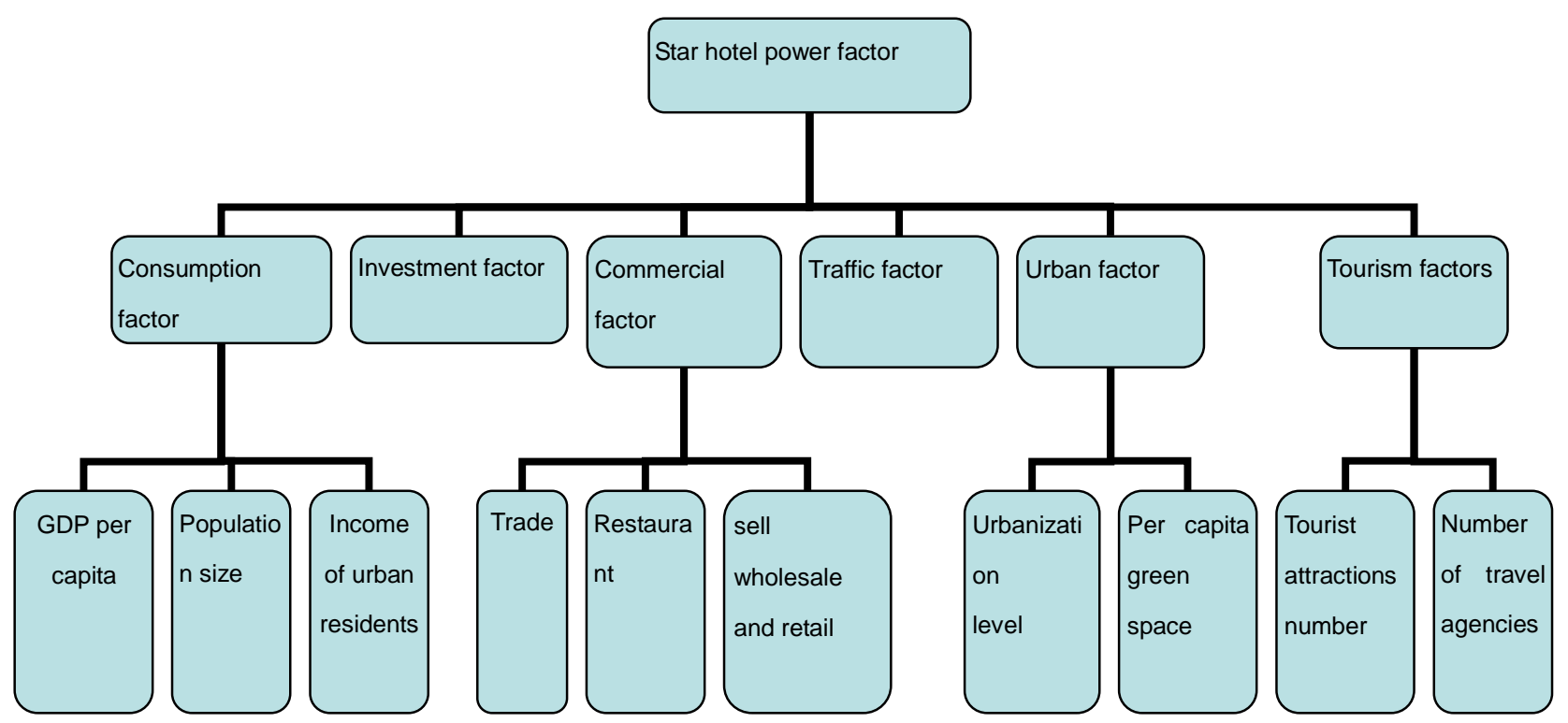

Fig 3 Construction of Dynamic Model of Chinese Star Hotels

Figure 3 constructs the influence of star hotels in China power system, can through the correlation analysis between each index and star hotel to further the correctness of the model establishment and the scientific nature ${ }^{[14]}$, at the same time can also through the related analysis to explore the fundamental factors that affect China's star hotel space layout, study its spatial structure adjustment and optimization law, is conducive to the development of China's hotel industry to a virtuous circle. This paper mainly uses the analysis method is Pearson correlation analysis ${ }^{[7]}$, the use of SPSS statistical analysis software for data analysis, the use of the data in 2012 to carry on analysis.

Table4 The Relationship Between the Number of Star Hotels in China and the Dynamic Factors of Pearson

\begin{tabular}{|c|c|c|c|c|c|c|c|c|}
\hline & \multicolumn{5}{|c|}{ Consumption factor } & \multicolumn{3}{|c|}{ Tourism factor } \\
\hline & $\begin{array}{c}\text { Income of urban } \\
\text { residents }\end{array}$ & \multicolumn{2}{|c|}{ GDP per capita } & \multicolumn{2}{|c|}{ Population size } & \multicolumn{2}{|c|}{ Tourist attractions number } & $\begin{array}{c}\text { Number of travel } \\
\text { agencies }\end{array}$ \\
\hline Pearson C & 0.398 & & 0.398 & & & & 0.479 & 0.875 \\
\hline \multirow[t]{3}{*}{ Sig.(2-tailed) } & 0.026 & & 0.026 & & & & 0.006 & 0.000 \\
\hline & \multicolumn{2}{|c|}{ Commercial factor } & \multicolumn{2}{|c|}{ Traffic factor } & \multicolumn{3}{|c|}{ City factor } & Investment factor \\
\hline & $\begin{array}{c}\text { Wholesale and } 1 \\
\text { trade }\end{array}$ & & \multicolumn{2}{|c|}{ Traffic conditions } & $\begin{array}{l}\text { Per } ~ \\
\text { green }\end{array}$ & & $\begin{array}{c}\text { Urbanization } \\
\text { level }\end{array}$ & Investment amount \\
\hline Pearson C & 0.788 & \multicolumn{3}{|c|}{0.572} & \multicolumn{2}{|c|}{0.037} & 0.166 & 0.820 \\
\hline Sig.(2-tailed) & 0.000 & \multicolumn{3}{|c|}{0.001} & 0.8 & & 0.418 & 0.000 \\
\hline
\end{tabular}

Data sources: 《China Statistical Yearbook》and 《China's tourism statistics yearbook》In2012, In 2013, In 2014.

From table 4 star hotel and various dynamic factors of Pearson correlation coefficient, the six dynamic factors except urban factor the rest of the various factors and correlation of star hotel number is higher, this explains dynamic system has a certain scientific research building, chooses the interpretation of the factor index also has certain representativeness, the power factor and star hotel correlation factor, followed by tourism investment factors, business factors, consumer factors and traffic factors and urban factors. 


\section{Conclusion}

(1) From the perspective of the space distribution of China's star hotel, ladder shaped from the east side to the west development, the gap between high-end and low-end is bigger.

(2) From the point of the time distribution of China's star hotel, the Midwest star-rated hotel industry to rise rapidly in the eastern region, in star hotel, the dynamic changes of the regional differences emerged two prominent features: First of all, the relative difference of development of star hotel industry continues to narrow; Second, during this period of China's star hotel industry is still a huge regional differences, even though the central and western regions of the star hotel industry revenue growth faster, but due to the low starting point, the total small, the absolute difference with the eastern region has been constantly .

(3) The spatial and temporal distribution of star-hotels in China is different from that of regional economy, especially the imbalance of tourism development. This reflects the hotel industry depends on the economic level and tourism, on the other hand also shows the development of star hotel has its own characteristics.

(4) The degree of difference between eastern and western star hotel development, shows that the Chinese government to implement the western development, the necessity of the rise of central China, only greatly driven the rapid development of economy of the central and western regions, time and space distribution pattern of star hotel development will have great changes, and gradually moves towards harmonious.

\section{References:}

[1] Ji Wen. On Chinese Star-Hotels' Spatial Distribution[J]. COMMERCLAL RESEARCH, 2004, (21): 154-159.

[2] Ruilin Yu, Hong Zhang. The Study of Spatial Distribution of Star Hotels In Wuhan Cit y[J]. YUNANGEOGRAPHIC ENVIRONMENT RESEARCH, 2006, (7): 90-94.

[3] Haining Jiang, Renxu Gu, Guangbin Li, et al. Research on Spatial Pattern of Accessibil ity about Star-rated Hotels in Nanjing City[J]. AREAL RESEARCH AND DEVELOP MENT, 2012,31(2):129-134,140.

[4] Wei Tao, Hengyu Gu, Haonan Chen. Guangzhou's Spatial Distribution under the Effec $\mathrm{t}$ of the Urban Road Network on the Hotel Industry[J]. 2015,30(10):99-108.

[5] David J Egan, Kevin Niekd. Towards a theory of intra urban hotel location[J]. Urban st udies, 2000, 37(3):611-621.

[6] Youyin Zhang, Jing Gu, Heqing Huang. Research on Regional Tourism Industry Structur al Differenceof China[J]. ECONOMIC GEOGRAPHY, 2012, 32(4): 155-1159,172.

[7] Peiyang Chen, Xigang Zhu. Regional Inequalities in China at Different Scales[J]. ACTA GEOGRAPHICA SINICA,2012,67(8):1085-1097.

[8] Lin Mei , Lei Han. A Study Into The Factors Influencing The Spatial Distribution Of S tar- Rated Hotels In China[J]. ECONOMIC GEOGRAPHY, 2011,31(9):1580-1584.

[9] $\mathrm{Hu} \mathrm{Yu}$, Lin Lu, Dongfang Zhu, et al. Urban Tourism to Urban Agglomeration Tourism: A Deepening Systematic Research[J]. PROGRESS IN GEOGRAPHY, 2012, 31(8):1087-1 096.

[10] Jigang Bao, Xuemei Liu. An Analysis of The Driving Factors of Urban Inbound Tourism in Guangdong[J]. TOURISM TRIBUNE, 2002(1):44-48.

[11] John Fei,Gustav Rains,Shirley Kuo. Growth and the family distribution of income by $\mathrm{f}$ 
actor components[J].Quarterly Journal of Economics, 1979,92(4):17-53.

[12] R.E.Murphy. The central business district: a study in urban geography[M].Longman Pre ss, 1972:237-244.

[13] Joel A.C. Baum, Heather A,Haveman. Differentiation and Agglomeration in the Manhat tan Hotel Industry,1898-1990 [J]. Administrative Science Quarterly, 1997, (42): 304-338.

[14] Jianya Gong, Xiaolong Li, Huayi Wu.Spatiotemporal Data Model for Real-time GIS[J]. Acta Geodaetica et Cartographica Sinica,2014, 43(3): 226-232. 